\title{
AS PERCEPÇÕES DE PROFESSORES SOBRE AS CONTRIBUIÇÕES DA PSICOLOGIA HISTÓRICO- CULTURAL A EDUCAÇÃO DO CAMPO MEDIANTE O PROGRAMA ESCOLA NEUROPSIEDUCAÇÃO (PENEUROPSIE)
}

\author{
LAS PERCEPCIONES DE LOS DOCENTES SOBRE LAS \\ CONTRIBUICIONES DE LA PSICOLOGÍA HISTÓRICO- \\ CULTURAL LA EDUCACIÓN DEL CAMPO ATRAVÉS DEL \\ PROGRAMA ESCOLA NEUROPSIEDUCAÇÃO \\ (PENEUROPSIE)
}

Tatiane Gamarra Calonga ${ }^{1}$ Maria Luzia da Silva Santana ${ }^{2}$

\section{RESUMO}

Há carência de estudos no contexto brasileiro que dialoguem acerca da Educação do Campo e a Psicologia Rural, por isso esta pesquisa aborda as contribuições da Psicologia da Educação para a formação de professores, a partir da Psicologia Histórico-Cultural articulada à Educação do Campo. O objetivo geral é investigar as contribuições da Psicologia da Educação à Educação do Campo, mediante a apresentação do Programa Escola Neuropsieducação (PENeuroPsiE). A metodologia de pesquisa utilizada agregou a revisão bibliográfica e a exploração dos dados, com a participação de 05 professores (as) que atuam ou atuaram na Educação do Campo. Os instrumentos utilizados para coleta de dados foram: vídeo, o PENeuroPsiE e um questionário no Google Forms. Foi evidenciado a importância da inserção da Psicologia da Educação no curso de formação de professores para atuar na Educação do Campo de maneira interdisciplinar, reflexiva e articulada ao contexto, ou seja, numa práxis pedagógica considerando uma reflexão acerca da realidade dos estudantes e das escolas em contextos rurais. O material pedagógico do PENeuroPsiE foi considerado relevante, inovador e motivador para o desenvolvimento das funções psicológicas superiores e apropriação dos conhecimentos abordados. Contudo, há necessidade de adaptar os recursos do PENeuroPsiE à realidade vivenciada pelos estudantes em assentamentos de reforma agrária e a Pedagogia da Alternância. As percepções dos professores sobre os materiais do PENeuroPsiE são importantes para ajustes e sua validação ecológica. Os dados obtidos colaboram com avanço, debates e reflexões sobre as contribuições da Psicologia Histórico-Cultural e Psicologia Rural à Educação do Campo.

\footnotetext{
${ }^{1}$ Graduanda em Pedagogia pela Universidade Federal de Mato Grosso do Sul, Mato Grosso do Sul, E-mail: tatianecalonga71@gmail.com, Orcid: https://orcid.org/0000-0002-0686-4112.

${ }^{2}$ Orientadora do trabalho, Doutora e Mestra em Psicologia pela Universidade Católica de Brasília, é professora adjunta na Universidade Federal de Mato Grosso do Sul/UFMS e compõe o quadro de docente do Programa de Pós-Graduação em Educação da FAED/UFMS. É líder do grupo de estudo e pesquisa em Psicologia, Processos Educativos e Inclusão (PPEI/CNPq/UFMS). E-mail: santanapsi@gmail.com, Orcid.: https://orcid.org/0000-00015151-3680.

Este trabalho foi financiado pelo CNPq, vinculado ao Programa Institucional de Bolsas de Iniciação Cientifica (PIBIC).
} 
Palavras-chaves: Psicologia da educação. Psicologia Histórico-Cultural. Materialismo histórico. Educação do campo. Formação de professores.

\section{RESUMEN}

Hay una falta de estudios en el contexto brasileno que dialoguen sobre Educación Rural y Psicología Rural, por lo que esta investigación aborda los aportes de la Psicología de la Educación a la formación docente, a partir de la Psicología Cultural -Histórica articulada a la Educación Rural. El objetivo general es investigar las contribuiciones de la Psicología de la Educación a la Educación Rural através de la presentación del Programa Escola Neuropsieducaçao (PEneuropsie). La metodologia de investigación utilizada incluyó uma revisión bibliográfica y exploración de datos, con la participación de 05 docentes (as) que trabajaron em Educación Rural. Los instrumentos utilizados para la recolección de datos fueron: vídeo, PENeuroPsiE y um cuestionario em Google Forms. A partir de los datos y las preposiciones de los autores que dialogan sobre este tema, la importância de inserir la Psicología Educativa em el curso de formación docente para trabajar em Educación Rural de manera interdisciplinaria, reflexiva y articulada, es de decir, em uma práxis pedagógica considerando uma reflexión sobre la realidade de los estudiantes y escuelas em contextos rurales. El material pedagógico de PENeuroPsiE se considero relevante, inovador y motivador para el desarrollo de funciones psicológicas superiores y la apropiación de los conocimientos cubiertos. Sin embargo, es necessário adaptar los recursos de PENeuroPsiE a la realidade vivida por los estudiantes em los asentamientos de reforma agraria y la pedagogia de la alternância. Las percepciones de los profesores sobre los materialies de PENeuroPsiE son importantes para los ajustes y su validación ecológica. Los datos obtenidos colaboran com el avance, debates y reflexiones sobre los aportes de la Psicología Cultural -Histórica y la Psicología Rural a la Educación Rural, además de contribuir a la formación docente.

Palabras clave: Psicología Educacional. Psicología Cultural -Histórica. Materialismo histórico. Educación rural. Formación de profesores.

\section{INTRODUÇÃO}

A educação brasileira é marcada pelo sistema hegemônico capitalista, tendo sua fundamentação num paradigma de exploração dos conhecimentos da natureza, em que predomina a dominação e desvalorização das classes sociais desfavorecidas (CHAMON, 2016). Esta perspectiva tem influenciado a formação educacional técnica dos indivíduos marginalizados, que é direcionada para atender às necessidades do mercado produtivo, consequentemente, influencia a manutenção das desigualdades sociais.

A Pedagogia Histórico-Crítico surgiu em contraposição ao sistema hegemônico capitalista, baseada nas ideias marxistas, busca a superação das sociedades de classes e exploração, de forma que ocorra a transformação da sociedade e humanização dos homens através de uma educação que universalize os conhecimentos científicos, para que todos possam ter acesso de maneira igualitária (MAZZEU, 2007). A educação na vertente da pedagogia histórico-crítico:

[...] significa pensar a educação comprometida com a socialização do saber elaborado, pautada por uma prática orientada por fins que contribuam para a 

decorrentes das relações sociais de dominação e, por isso, superáveis (MAZZEU, 2007, p.51)

Na oposição a esta vertente histórico-crítico, inicialmente a Psicologia da Educação pautou-se no uso de testes e avaliações, numa tendência reducionista, que atribuía ao estudante a determinação de seus "problemas", sem considerar outros fatores, tais como, as condições pedagógicas, culpabilizando os indivíduos e suas famílias pelas dificuldades de aprendizagem (ANTUNES, 2008). Isso colaborava para que as crianças de classes populares não tivessem uma educação de qualidade, sendo desconsideradas as dimensões sociais, políticas e pedagógicas que influenciavam no processo de ensino e aprendizagem. A partir disso, são relevantes o compromisso e a perspectiva crítica da psicologia educacional e escolar para com as classes populares, com o intuito de construir uma sociedade democrática (ANTUNES, 2008).

Portanto, a Psicologia Educacional "deve propiciar a compreensão do educando a partir da perspectiva de classe e em suas condições concretas de vida, condição necessária para se construir uma prática pedagógica realmente inclusiva e transformadora" (ANTUNES, 2008, p.474). Neste viés é imprescindível considerar a abordagem crítica da Psicologia Histórico-Cultural na formação e prática pedagógica dos professores, para que compreendam os elementos históricos, econômicos, sociais e culturais envolvidas no processo educativo.

A concepção de educação na vertente da Psicologia Histórico-Cultural considera que as relações sociais, historicamente construídas pela humanidade, interferem na aprendizagem e desenvolvimento dos seres humanos. Martins (2014, p. 91) aponta que “[...] Vygotski se opôs aos modelos que prescreviam o desenvolvimento de forma unilateral e linear, como sucessão de fases naturalmente predeterminadas, expressas mediante o acúmulo lento e gradual de mudanças isoladas". Desse modo, somente o sistema biológico não é o suficiente para o homem se apropriar de determinada cultura, sendo necessário que ocorra estímulos exteriores para sua aprendizagem e desenvolvimento.

Nessa vertente o homem torna-se verdadeiramente humano com o entrelaçamento do biológico e cultural, no sentido de que ele não nasce humanizado, mas torna-se a partir da interação com o seu meio e apropriação da cultura histórica (MORETTI; ASBAHR; RIGON, 2011). Logo, a identidade histórica e cultural do homem se constitui a partir do contexto que ele está inserido e através das mediações recebidas ao longo da vida. No contexto escolar, a forma como o professor planeja e executa a sua prática pedagógica influência no desenvolvimento das funções psicológicas superiores e apropriação dos conhecimentos científicos por parte dos estudantes. 
Para ocorrer a socialização dos conhecimentos, importantes na constituição de todos os indivíduos nas instituições de ensino, é necessário refletir como estão sendo formados os professores que necessitam de uma base teórica concreta, sustentada pela reflexão filosófica e conhecimentos científicos, de modo que compreendam o processo de constituição do homem em sua totalidade (SAVIANI, 1995 apud PASQUALINI; MAZZEU, 2008). Neste aspecto, busca-se compreender acerca das contribuições da Psicologia da Educação na formação de professores, sobretudo, a partir da vertente da Psicologia Histórico-Cultural articulada a Educação do Campo. Assim, será investigado como a Psicologia da Educação contribui com as ações pedagógicas em contexto de educação, localizados na zona rural.

A Educação do Campo é marcada por lutas e movimentos sociais em prol dos direitos das pessoas que moram no campo, dentre eles a escolarização contextualizada. Os militantes do Movimento dos Trabalhadores Rurais (MST) buscaram uma educação que considere a diversidade cultural e apropriação de conhecimentos, através de uma mudança educacional "adaptada e adequada às condições do meio rural e entendida, como instrumento capaz de libertar a classe trabalhadora da exploração a que está submetida, provendo assim o acesso ao saber àqueles que foram de alguma forma, excluídos da sociedade capitalista" (NETOBEZERRA, 2010, p. 150).

A articulação da temática Psicologia da Educação e Educação do Campo é carente de estudos no contexto brasileiro, por isso pesquisas acerca dessas áreas na articulação com a Psicologia Rural, considerando as dimensões psicológicas e as particularidades dos sujeitos que no campo habitam, são necessárias e justifica a presente pesquisa. Com essa intenção, este Trabalho de Conclusão de Curso, oriundo do Programa Institucional de Bolsas de Iniciação Científica (PIBIC) e vinculado ao projeto guarda-chuva "Programa Escola Neuropsieducação (PENeuroPsiE) " dialoga sobre Psicologia e Educação do Campo.

O "Programa Escola Neuropsieducação (PENeuroPsiE) " visa construir ações e materiais pedagógicos relacionado às neurociências e aprendizagem, considerando a formação inicial e continuada de professores, assim como os estudantes do $5^{\circ}$ ano do ensino fundamental I (SANTANA, 2019a), para isso, buscou amparo teórico na Psicologia HistóricoCultural. Também problematiza a constituição dos processos psicológicos superiores, considerando que o cérebro é ferramenta para o funcionamento psicológico sendo ele biológico-sócio-histórico-cultural.

\section{Método}

Essa pesquisa foi submetida ao comitê de ética em pesquisa da Universidade Federal de Mato Grosso do Sul e obteve a aprovação sob o parecer no. 3.225.932. A metodologia de 
pesquisa utilizada agregou a revisão bibliográfica e a exploração dos dados de 05 professoras que atuam ou atuaram na área da Educação do Campo.

A pesquisa bibliográfica utilizou de artigos, dissertações, teses e livros acerca dos temas abordados, encontrados na base de dados Portal Capes, SciELO e Google Acadêmico. Para Lakatos e Marconi (2003, p.158) “a pesquisa bibliográfica é um apanhado geral sobre os principais trabalhos já realizados, revestidos de importância, por serem capazes de fornecer dados atuais e relevantes relacionados com o tema".

Também foi realizada pesquisa qualitativa e exploratória com a coleta de dados mediante questionário eletrônico. Num estudo qualitativo a análise dos dados "depende de muitos fatores, tais como a natureza dos dados coletados, a extensão da amostra, os instrumentos de pesquisa e os pressupostos teóricos que nortearam a investigação" (GIL, 2002, p.134).

Assim, foram organizados em uma sequência de atividades que consistiu em redução dos dados, categorização, interpretação e escrita (GIL, 2001). Para Gil (2008) o objetivo da pesquisa exploratória é ter uma visão ampla sobre um determinado assunto que carece de estudos, portanto "este tipo de pesquisa é realizado especialmente quando o tema escolhido é pouco explorado e torna-se difícil sobre ele formular hipóteses precisas e operacionalizáveis" (GIL, 2008, p.27).

\subsection{Participantes e local da pesquisa}

Essa pesquisa envolveu 05 professores (as) que atuavam com a Educação do Campo, em três regiões do Brasil. Os critérios para a seleção desses profissionais foram mediante atuação em escolas públicas do campo. Os professores foram identificados de acordo com a ordem das respostas analisadas sendo: P1, P2, P3, P4 e P5, na tabela abaixo é apresentado o sexo, idade, formação, trajetória profissional, quantidade de locais que lecionam, carga horária de trabalho e município/estado dos participantes.

Quadro 1: Caracterização dos participantes do estudo

\begin{tabular}{|l|l|l|l|l|l|l|l|}
\hline $\begin{array}{l}\text { Partici } \\
\text { pantes }\end{array}$ & Sexo & Idade & Formação & $\begin{array}{l}\text { Trajetória } \\
\text { profissiona } \\
1\end{array}$ & $\begin{array}{l}\text { Locais } \\
\text { que } \\
\text { leciona }\end{array}$ & $\begin{array}{l}\text { Carga } \\
\text { horári } \\
\text { a }\end{array}$ & $\begin{array}{l}\text { Município } \\
\text { / Estado }\end{array}$ \\
\hline P1 & $\begin{array}{l}\text { Masculin } \\
\text { o }\end{array}$ & $\begin{array}{l}\text { Entre } 30- \\
40 \text { anos }\end{array}$ & $\begin{array}{l}\text { Licenciatura } \\
\text { Eeografia }\end{array}$ & $\begin{array}{l}\text { Entre 10- } \\
15 \text { anos }\end{array}$ & $\begin{array}{l}\text { Em uma } \\
\text { escola }\end{array}$ & $\begin{array}{l}30 \\
\text { horas }\end{array}$ & Goiás/GO \\
\hline P2 & Feminino & $\begin{array}{l}\text { Mais que } \\
60 \text { anos }\end{array}$ & $\begin{array}{l}\text { Pedagoga - } \\
\text { Doutora em }\end{array}$ & $\begin{array}{l}\text { Entre 15- } \\
20 \text { anos }\end{array}$ & $\begin{array}{l}\text { Em uma } \\
\text { escola }\end{array}$ & $\begin{array}{l}30 \\
\text { horas }\end{array}$ & $\begin{array}{l}\text { Curitiba/P } \\
\mathrm{R}\end{array}$ \\
\hline
\end{tabular}



Mediante o Programa Escola Neuropsieducação (Peneuropsie)

\begin{tabular}{|l|l|l|l|l|l|l|l|}
\hline & & & Educação & & & & \\
\hline P3 & Feminino & $\begin{array}{l}\text { Entre 30- } \\
40 \text { anos }\end{array}$ & $\begin{array}{l}\text { Magistério, } \\
\text { História e } \\
\text { Ed. do } \\
\text { Campo }\end{array}$ & $\begin{array}{l}\text { Entre 15- } \\
20 \text { anos }\end{array}$ & $\begin{array}{l}\text { Em uma } \\
\text { escola } \\
\text { Poras }\end{array}$ & $\begin{array}{l}\text { Nova } \\
\text { Santa } \\
\text { Rita/RS }\end{array}$ \\
\hline P4 & Feminino & $\begin{array}{l}\text { Entre 30- } \\
40 \text { anos }\end{array}$ & $\begin{array}{l}\text { Educação } \\
\text { do Campo - } \\
\text { Ciências da } \\
\text { Natureza }\end{array}$ & $\begin{array}{l}\text { Menos que } \\
5 \text { anos }\end{array}$ & $\begin{array}{l}\text { Em uma } \\
\text { escola }\end{array}$ & $\begin{array}{l}\text { Meno } \\
\text { s que } \\
\text { 20 } \\
\text { horas }\end{array}$ & $\begin{array}{l}\text { Santa Cruz } \\
\text { do Sul/RS }\end{array}$ \\
\hline P5 & Feminino & $\begin{array}{l}\text { Entre 30- } \\
40 \text { anos }\end{array}$ & $\begin{array}{l}\text { Educação } \\
\text { do Campo }\end{array}$ & $\begin{array}{l}\text { Menos que } \\
5 \text { anos }\end{array}$ & $\begin{array}{l}\text { Em duas } \\
\text { escolas }\end{array}$ & $\begin{array}{l}20 \\
\text { horas }\end{array}$ & $\begin{array}{l}\text { Gravataí/R } \\
\text { S }\end{array}$ \\
\hline
\end{tabular}

Fonte: Construído pela autora (2020).

Cabe esclarecer apenas P3 já estudou em escolas do campo, ensino fundamental, no $2^{\circ}$ Ano. Porém, todos os demais participantes deste estudo mantêm alguma relação com a Educação do Campo, ou através do exercício profissional com professora em escolas do campo ou mediante a realização de estudos na temática.

\subsection{Instrumentos}

Os instrumentos utilizados para coleta de dados deste estudo foram: o Programa Escola Neuropsieducação (PENeuroPsiE), vídeo e um questionário no Google Forms.

O Programa Escola Neuropsieducação-PENeuroPsiE visa compreender os processos de ensino e aprendizagem e para isso embasou-se em teóricos das neurociências, educação e Psicologia Histórico-Cultural. O PENeuroPsiE possui três livros na versão preliminar, jogos digitais, o Fantástico Museu Cerebral (realidade virtual), uma Sequência Pedagógica PENeuroPsiE para estudantes do $5^{\circ}$ Ano do Ensino Fundamental e uma proposta de Curso de formação inicial e continuada para professores (SANTANA, 2019a).

$\mathrm{O}$ vídeo foi produzido pelos acadêmicos que fizeram parte do Projeto de Extensão "Programa Escola Neuropsieducação (PENeuroPsiE)" em substituição à apresentação presencial do PENeuroPsiE aos professores, em decorrência das medidas de segurança causadas pela emergência de saúde pública, gerada pelo surto da doença Covid-19. No vídeo foram apresentados os objetivos do PENeuroPsiE, os materiais pedagógicos, a sequência didática realizada com estudantes do 5 Ano do Ensino Fundamental I, o curso de formação inicial e continuada de professores e os resultados preliminares das ações de extensão 
realizadas com a utilização do kit PENeuroPsiE. Assim, expõe as ações que foram desenvolvidas com os estudantes do $5^{\circ}$ ano e professores para avaliar e ajustar os materiais desenvolvidos.

\subsection{Coleta e análise de dados}

A coleta dos dados iniciou com a realização de um levantamento de e-mails de professores que de alguma maneira atuaram na área da Educação do Campo, com o posterior envio do convite e formulário para participar e responder o questionário da pesquisa como voluntários. Neste formulário foi solicitado que eles assistissem ao vídeo que apresenta o material que compõe PENEuroPsiE e fizessem a leitura do livro dos estudantes em formato PDF.

Posteriormente, eles responderam o questionário acerca das contribuições da psicologia à educação em contexto de escolas rurais, considerando o Programa Escola Neuropsieducação (PENeuroPsiE) e as ações pedagógicas que podem ser realizadas usando este material com estudantes do $5^{\circ}$ Ano do Ensino Fundamental I.

Os dados obtidos passaram por leitura, seleção e organização. Após isso, foram analisados e interpretados a partir da leitura da Psicologia Histórico-Cultural, foram organizados em duas categorias: Contribuições da Psicologia da Educação à Educação do Campo, segundo a concepção dos professores; e Percepções de professores sobre os recursos pedagógicos do PENeuropsiE para estudantes em escolas do campo, apresentadas na seção seguinte.

\section{Resultados e discussão}

Os dados obtidos possibilitaram identificar dois eixos de análise. Um dialoga acerca da psicologia da educação e suas contribuições na educação do campo, considerando as concepções dos participantes deste estudo. Outro eixo centrou nos recursos pedagógicos do PENeuropsiE visando verificar a adequabilidade deles para estudantes em escolas do campo.

3.1 contribuições da psicologia da educação para a educação do campo segundo a concepção dos professores

A psicologia é um dos fundamentos da educação, inicialmente pautou suas ações no modelo médico e numa tendência reducionista voltada a adaptação e ajustamento dos estudantes nos modelos sociais esperados e para solucionar os problemas de aprendizagem. 
As teorias psicológicas de aprendizagem explicavam esses problemas somente considerando a formação psíquica do próprio estudante e de suas famílias sem considerar as dimensões sociais, culturais, afetivas, econômica e políticas que interferem no processo de aprendizagem (ZUCOLOTO, 2018).

Essas práticas denominadas de psicologização da educação foram criticadas a partir dos anos de 1970 por pedagogos e psicólogos (ANTUNES, 2008). Entre os contributos da psicologia na formação de professores está a compreensão da aprendizagem e desenvolvimento dos estudantes a partir de diferentes teorias (ALVES, 1997). Os participantes da pesquisa evidenciaram sobre a finalidade da psicologia da educação.

\footnotetext{
De auxiliar os profissionais seja em sala de aula ou no âmbito escolar (P1)

Possibilitar a compreensão acerca do desenvolvimento humano e da possibilidade de promover a aprendizagem e desenvolvimento da capacidade humana (P2).

Observar os educandos e traçar planos de ensino aprendizagens que sejam igualitários (P5).

Compreensão da diversidade do ser humano, tanto de aprendizagem como de personalidade. Formas de tentar entender comportamentos que são reflexos das suas experiências vividas, que são diversas ( $\mathrm{P} 4)$.

Ajudar na compreensão e desenvolvimento (P3).

Perceber e entender os comportamentos dos alunos e auxiliar enquanto professor (P1).

Auxiliar o professor na compreensão da subjetividade dos alunos, entendendo os processos individuais de desenvolvimento (P2).

Pode ajudar muito o processo de ensino aprendizagens (P5).
}

Como nos afirma Silva e Nascimento (2013, p.110) “[...] a Psicologia da Educação estuda como nascem e se ampliam as funções psíquicas que distingue o homem dos animais, ou seja, a evolução de suas capacidades intelectuais, perceptuais, motoras, sociais e afetivas" e se constitui "como um dos fundamentos científicos da educação e da prática pedagógica" (ANTUNES, 2008, p. 469). As teorias psicológicas explicitam como ocorre os processos de aprendizagem e desenvolvimento dos indivíduos em sua totalidade, considerando os processos internos e externos.

O estudo de Santana (2019) problematiza a psicologia da educação em contexto de escolas do campo, área carente de debate que requer articulações necessárias em seus aspectos teóricos-metodológico entre a educação do campo, psicologia educacional e escolar e a psicologia rural. A psicologia rural é uma área que ainda está em processo de constituição. A história da psicologia aponta que em contextos rurais não foram considerados as especificidades das pessoas destes locais, assim as investigações, experimentações e estudos estiveram voltadas para a área urbana, seus resultados foram generalizados e indicam a invisibilidade das comunidades de contextos rurais (LANDINI, 2015). 
Nota-se, portanto, o processo de marginalização da população do campo com o uso de modelos e instrumentos construídos para população urbana que, consequentemente, não foram consideradas as peculiaridades dos povos que moram nas comunidades rurais. Os movimentos sociais em busca do espaço, direitos e valorização dos sujeitos do campo, também influenciaram e possibilitam novos olhares na área da psicologia em contexto rural (LANDINI, 2015). Porém, pressupõe que ainda é insuficiente para atender as demandas educativas, superação da desigualdade social e o acesso a conhecimentos científicos para essa população, que historicamente ficou à margem da sociedade.

Cabe ainda ressaltar as ideias de Monteiro (2017), acerca de três tipos de ruralidades e suas especificidades. A primeira é apontada como uma população que vive em extrema pobreza, a segunda são as ruralidades enriquecidas pelo agronegócio que visa o crescimento econômico, e a terceira ruralidade é realmente rica com riqueza cultural, ambiental e cognitiva. Cada uma dessas ruralidades possui diferentes demandas educativas, que necessitam de intervenção diferenciada. Em conformidade com Monteiro (2017) a contribuição mais importante da psicologia e da psicologia rural para a educação está relacionada com a ruralidade rica em seu sentido cultural.

A diversidade existente na população que mora na zona rural também perpassa as diferentes experiências dos professores que participaram da presente pesquisa, que situaram sua relação e as experiências que levaram a escolas ou área da educação do campo. Ao observar a as descrições deles é possível sugerir o espaço aberto e em construção na educação do campo para a realização de projetos voltados ao seu desenvolvimento (Quadro 2).

Quadro 2: Relação e experiências em escolas ou área da Educação do Campo.

\begin{tabular}{|l|l|}
\hline Participantes & \multicolumn{1}{|c|}{ Relação e experiências em escolas ou área da Educação do Campo } \\
\hline P1 & $\begin{array}{l}\text { Na graduação pude conhecer e fazer estágio em Escola do Campo. } \\
\text { Na graduação conheci a Educação do Campo e na pós graduação pude } \\
\text { desenvolver projetos na Educação do Campo. Logo comecei a trabalhar na } \\
\text { Educação do Campo e estou até o presente momento. } \\
\text { Sou professor em uma Escola do Campo e supervisor do Programa } \\
\text { Residência Pedagógica ofertado por uma universidade, que desenvolve } \\
\text { ações nesta mesma escola. }\end{array}$ \\
\hline P2 & $\begin{array}{l}\text { Minhas pesquisas sobre o desenvolvimento do processo de ensino e } \\
\text { aprendizagem e as experiências familiares. Realizei minhas pesquisas no } \\
\text { mestrado e doutorado. Faço parte do Núcleo de Pesquisa em Educação do } \\
\text { Campo, Movimentos Sociais e Práticas Pedagógicas de uma universidade. }\end{array}$ \\
\hline P3 & $\begin{array}{l}\text { Estudou no Ensino fundamental, } 2^{\circ} \text { Ano na escola do campo. Minha avó } \\
\text { foi Professora em escola rural. Minha origem histórica na agricultura } \\
\text { familiar e a aproximação com os povos originários. }\end{array}$ \\
\hline P4 & $\begin{array}{l}\text { Tive a oportunidade de lecionar numa escola comunitária e no meio rural. } \\
\text { Assim surge a curiosidade em estudar uma temática (educação do campo) } \\
\text { tão familiar a minha vida. Sou pesquisadora da temática, desde minha }\end{array}$ \\
\hline
\end{tabular}




\begin{tabular}{|l|l|}
\hline & $\begin{array}{l}\text { dissertação, TCC e tese, além dos projetos de pesquisa e extensão que } \\
\text { desenvolvemos nas escolas durante a graduação. E os Tempos } \\
\text { Comunidades e Estágios Obrigatórios (ou não) que também eram } \\
\text { desenvolvidos em escolas no campo. }\end{array}$ \\
\hline P5 & $\begin{array}{l}\text { Trabalho e coordeno a escola do campo. Supervisora escolar inicialmente e } \\
\text { depois como gestora de uma escola em assentamento da reforma agrária. }\end{array}$ \\
\hline
\end{tabular}

Fonte: Construído pela autora (2020).

A maioria dos professores que participaram desta pesquisa tiveram contato com a área de educação do campo por meio estágio obrigatório, e de pesquisas desenvolvidas sobre a temática. Somente a P3 afirma ter estudado em escolas do campo e aproximação com os povos originários.

A educação é uma ferramenta que possibilita a emancipação dos sujeitos do campo (MURTAGH, 2015), mas para que isso se estabeleça é necessário um currículo que considere o modo de vida subjetivo, as relações sociais, culturais, tradições, saberes do campo, e não um currículo homogeneizador, alienante e transposto de contextos urbanos. Também é preciso considerar as contribuições da interdisciplinaridade no campo da educação do campo, que permitam refletir sobre as necessidades psico-sócio-cultural da população rural, uma vez que deve ocorrer estudos específicos e mediação diferenciada para a formação dos camponeses (MURTAGH, 2015).

Para a Psicologia Histórico-Cultural a aprendizagem e o desenvolvimento das funções psicológicas superiores ocorrem pelas interações sociais, utilizando de objetos e instrumentos para a apropriação da cultura e mudanças no comportamento humano. Martins (2014, p. 89) em seu estudo sobre as contribuições da psicologia histórico-cultural para a educação do campo, enfatiza sobre:

[...] os preceitos de "desnaturalização" do desenvolvimento psíquico e das diferentes formas de sua expressão; afirmação dos signos como estímulos que balizam a ação humana na realidade concreta; os tipos de atividades culturais dominantes condicionam a estrutura cognitiva dos indivíduos.

A partir do estudo de Martins (2014) percebe-se que com a educação rural homogênea/citadina ofertada nas mediações/interações para a população do campo, utiliza-se de instrumentos mediadores que estimulam o empoderamento da cultura dominante na formação do desenvolvimento psicológico, retirando a possibilidade de desenvolvimento do psiquismo baseado nas singularidades e na realidade concreta. Visto que para a emancipação do sujeito do campo é necessário compreendê-lo como um ser total, e lhe possibilitar uma visão de mundo ampla, consciência política e reconhecimento do seu papel social.

Bezerra-Neto (2010) enfatiza a importância dos sujeitos do campo conhecerem diferentes modos de produção dos conhecimentos científicos. Na perspectiva marxista, o qual 
é a base teórica da psicologia histórico-cultural de Vygotsky, é preciso entender a realidade para poder atuar sobre ela de modo transformador. Portanto, os sujeitos do campo só passarão a compreender a realidade que os cerca, discutir diferentes aspectos, como por exemplo, direitos econômicos e sociais, mediante a apropriação conhecimentos teóricos historicamente produzidos (NETO-BEZERRA, 2010). Essa ideia corrobora com o que afirma a P4 sobre a psicologia enquanto ciência e profissão, em uma instituição de ensino:

Permiti que os estudantes se enxerguem enquanto seres responsáveis pelas suas atitudes e que a sociedade é mais diversa que a localidade onde moram, e ainda que todas as pessoas e seres merecem respeito. Aos professores, permiti que se reconheçam enquanto classe trabalhadora e da necessidade de unidade profissional, que enxerguem a necessidade de união e compromisso com a educação, se desvencilhando de pré-conceitos retrógrados.

É neste sentido que Arroyo (2006) afirma que na formação de professores da Educação do Campo é necessário discutir sobre os diferentes modos de produção considerando diferentes paradigmas, e não se fundamentar somente no produto do conhecimento. A construção do conhecimento dos professores na área de psicologia da educação durante o curso de formação, aponta neste sentido, assim P1 e P4 afirmaram que contribui para compreender o processo de aprendizagem dos estudantes, sendo os conhecimentos de fundamentais importância para atuar na educação básica. Ainda P4 considerou relevante, em seu curso de formação, o debate de estruturas históricas que influenciam no comportamento dos indivíduos e a diversidade de aprendizagem, que refletem na psicologia da educação numa perspectiva crítica.

No curso de formação de professores essa perspectiva crítica da psicologia, representou um passo importante para o rompimento da ideia de adaptação e ajustamento de estudantes conforme os padrões esperados. É importante que o professor tenha uma postura pedagógica histórica e crítica frente às demandas de aprendizagem dos estudantes, possibilitando [...] "a compreensão do educando a partir da perspectiva de classe e em suas condições concretas de vida, condição necessária para se construir uma prática pedagógica realmente inclusiva e transformadora" (ANTUNES, 2008, p. 474).

A P5 formada em Magistério, Licenciatura em História e Educação do Campo/Ciências da Natureza, revela que aprendeu pouco sobre a psicologia da educação na graduação, devido não ser o foco de sua área de estudo, porém ao ingressar no contexto escolar e observar as dificuldades dos estudantes percebeu a necessidade de ter profissionais da área de psicologia atuando junto a escola. Além disso, buscou amparo teórico na aprendizagem significativa para compreender melhor o processo de ensino e aprendizagem. 
Com isso, percebe-se que além da área da psicologia da educação a psicologia escolar também é apontada como recurso importante, visando suprir as demandas do contexto escolar, podendo contribuir com o processo de aprendizagem e desenvolvimento dos estudantes e da escola como um todo. Esclarece-se que a psicologia educacional ou da educação abarca um conjunto de conhecimento "que pretende explicar e subsidiar a prática pedagógica, sendo, portanto, de domínio necessário para todos os educadores, e a psicologia escolar, como campo de atuação de profissionais da psicologia que atuariam no âmbito da escola, desempenhando uma função especifica, alicerçada na psicologia" e que inicialmente utilizou o modelo clínico de intervenção em contextos escolares (ANTUNES, 2008, p.472).

O estudo de Sant'Anna, Geber e Tetu (2019) investigou as contribuições da psicologia da educação na formação de professores mediante as percepções dos profissionais que atuam no ensino fundamental I. Os achados apontaram que os conhecimentos psicológicos de fato contribuem para a atuação do professor, contudo na formação dos participantes foi insuficiente, com um distanciamento entre a teoria e prática.

A pesquisa de Almeida e Azzi (2007) em instituições de ensino superior, com professores formadores do curso de matemática, buscou discutir a implantação da psicologia da educação no curso de formação de professores em contexto de reformas educacionais, e também analisou o lugar da psicologia como saber necessário. Os achados constataram que a maioria dos professores formadores apontou a necessidade de entender o desenvolvimento humano e saber como ocorre a aprendizagem, assim como essa disciplina se relaciona com outras ciências e a prática pedagógica. No entanto, é importante que a psicologia mantenha um diálogo com outras áreas do conhecimento que também contribuem para compreensão dos processos educativos, atrelando-se a outras ciências, pois os conhecimentos psicológicos voltados somente para sua aplicação na educação não garantem sua efetividade.

A partir dos dados obtidos e das preposições dos autores já situados evidencia-se a importância da inserção da psicologia da educação no curso de formação de professores da educação do campo de maneira interdisciplinar, reflexiva e articulada ao contexto, ou seja, numa práxis pedagógica para que ocorra uma reflexão acerca da realidade dos estudantes e das escolas em contextos rurais. Nessa perspectiva, esta área também é importante para o incremento de ferramentas para o processo de ensino-aprendizagem, uma vez que o professor ao conhecer os diferentes enfoques teóricos da psicologia da educação e ao entender sobre os processos de aprendizagem, desenvolvimento e seus determinantes será possível buscar metodologias adequadas à realidade e especificidade dos estudantes em escolas do campo. Contudo, "observa-se que a discussão acerca da psicologia escolar e educacional/educação e 
psicologia rural e suas contribuições para a educação do campo é tímida, constituindo-se isso como um dos desafios a ampliação do seu debate" (SANTANA, 2019, s./p.).

Sobre a finalidade da psicologia da educação na concepção dos professores do presente estudo todos confirmaram que as teorias psicológicas visam auxiliar no planejamento da prática pedagógica e compreensão do desenvolvimento/aprendizagem, comportamento, pensamento, sentimento de cada estudante. A P4 formada em educação do campo/ ciências da natureza cita a finalidade no trabalho pedagógico a compreensão da diversidade humana, no que se refere a aprendizagem e personalidade e também formas de compreensão de comportamentos resultado das vivências e experiências dos indivíduos.

Nota-se na descrição de P4 elementos que se aproximam da Psicologia HistóricoCultural, ao apontar a necessidade de considerar as dimensões sociais que envolvem os indivíduos do campo para um ensino e aprendizagem voltado para a formação humana. Assim como a P2 que evidenciou a contribuição da psicologia da educação como um caminho para "compreender os fatores internos e externos que interferem no desenvolvimento dos sujeitos, contribuindo para a organização de estratégias e recursos que otimizem o processo de ensino e aprendizagem".

A aproximação dos participantes desta pesquisa com uma leitura crítica na vertente da Psicologia Histórico-Cultural é percebida, nas ponderações sobre a concepção sobre o que a psicologia, enquanto ciência e profissão, pode realizar numa instituição de ensino/escola sinalizando que a possibilita. E também sobre e planejamento das aulas e os conhecimentos da área da psicologia da educação, do desenvolvimento e aprendizagem.

\footnotetext{
Os estudantes se enxerguem enquanto seres responsáveis pelas suas atitudes e que a sociedade é mais diversa que a localidade onde moram, e ainda que todas as pessoas e seres merecem respeito aos professores, permitir que se reconheçam enquanto classe trabalhadora e da necessidade de unidade profissional, que enxerguem a necessidade de união e compromisso com a educação, se desvencilhando de préconceitos retrógrados $(\mathrm{P} 4)$.
}

Principalmente, os conhecimentos que possibilitaram entender cada aluno como um sujeito singular, cujo desenvolvimento depende de fatores relacionados à sua história e forma de funcionamento; cada um tem uma modalidade de aprendizagem. Isto precisa ser considerado para que se possa utilizar recursos e estratégias que assegurem as diferentes formas de aprender (P2).

A Psicologia Histórico-Cultural considera o homem em sua totalidade, e isso deve refletir na ação educativa intencional. O professor necessita compreender que o estudante traz consigo um conjunto de saberes culturais para o contexto da escola, que devem ser valorizados e ampliados para construção de novos conhecimentos. Assim, "nessa perspectiva 
teórica a educação é entendida não como mera aquisição de conteúdos ou habilidades específicas, mas como uma via para o desenvolvimento psíquico e principalmente humano" (MORETTI; ASBAHR; RIGON, 2011, p. 481).

Houve o consenso entre os professores quanto ao uso, em algum momento, de conhecimentos da psicologia da educação e do desenvolvimento e aprendizagem para embasar suas práticas pedagógicas. Através da psicologia da educação afirmam que trabalham com o preconceito, bullying, jogos que estimulam as funções cerebrais, sentimento, reflexão e a aprendizagem significativa. A P2 afirma que busca:

Os conhecimentos que possibilitam entender cada aluno como um sujeito singular, cujo desenvolvimento de fatores relacionados a sua história e forma de funcionamento, pois cada um tem uma modalidade de aprendizagem. Isto precisa ser considerado para que se possa utilizar recursos e estratégias que assegurem as diferentes formas de aprender.

Essa expressão sugere a necessidade de uma psicologia rural para atender os desafios em contextos latino americanos, especificamente no Brasil. É relevante a defesa e constituição de uma psicologia rural que considere os processos subjetivos que compõem a população que reside em contextos rurais, para isso é importante estudos com um olhar mais amplo para as demandas sociais e educativas deste contexto (LANDINI, 2015).

Segundo Santana (2019, s/p.) “mesmo existindo lacuna, há investimentos de práticas, estudos e pesquisas na área da psicologia em contextos rurais brasileiros. Observou-se, em alguns estudos, que os temas abordados incluem aspectos metodológico da pesquisa, assim como saúde, políticas públicas e educação". Visando ampliar as discussões nesta área são apresentadas as concepções dos professores sobre o Programa Escola PENeuroPsiE, que busca contribuir para a formação inicial e continuada de professores para aprimorar estratégias de ensino-aprendizagem, voltadas às interações e mediações pedagógicas para a Educação do Campo.

3.2 percepções de professores sobre os recursos pedagógicos do peneuropsie para estudantes em escolas do campo

Pensar na formação dos professores que atuam em contexto rurais a partir da psicologia da educação, torna-se relevante para a reflexão dos professores em relação às contribuições da Psicologia Histórico-Cultural e Psicologia Rural no processo educativo. A partir do PENeuroPsiE busca problematizar a psicologia da educação como uma área que contribuiu para formação do professor reconhecendo este "como sujeito do processo educativo, traduzindo-se na necessidade de mudanças profundas das políticas de formação inicial e continuada desse protagonista fundamental da educação" (ANTUNES, 2008, p. 474). 
O Programa Escola Neuropsieducação-PENeuroPsiE centra nos processos de ensino e aprendizagem, para isso embasou-se em neurociências, educação e psicologia. Este programa em sua versão preliminar conta com produtos pedagógicos tendo como teoria de base a Psicologia Histórico-Cultural. O kit PENeuroPsiE possui três livros na versão preliminar, jogos digitais, o Fantástico Museu Cerebral (realidade virtual), Sequência Pedagógica PENeuroPsiE para estudantes do 5 Ano do Ensino Fundamental e curso de formação inicial e continuada de professores.

Dentre esses recursos foram enviados para os professores o livro destinado aos estudantes "Estudantes em ação - aprender pela curiosidade e criatividade: as neurociências, aprendizagem, desenvolvimento e os processos psicológicos superiores em foco (Livro 3) " nele é apresentado conceitos de neurociências em uma linguagem compreensível por crianças. No contexto do livro é apresentado noções básicas do desenvolvimento do sistema nervoso, frisando os processos psicológicos superiores como: memória, atenção, emoção, inteligência, linguagem e pensamento.

Observou se a concepção dos professores ao que se refere a relevância, fundamentação teórica e outras áreas do conhecimento pertinentes para estudantes do $5^{\circ}$ ano do ensino fundamental presentes no material pedagógico do PENeuroPsiE. Neste sentido, P1 e P5 afirmaram que estes materiais contribuem para o processo de ensino/aprendizagem, desenvolvimento e percepção dos estudantes em relação aos conhecimentos abordados. Sobre o livro a P2 relatou:

\footnotetext{
Acho muito interessante, pois a compreensão sobre o funcionamento cerebral é imprescindível para um profissional de educação, de modo a desenvolver uma prática que possibilite aos seus alunos a otimização do seu potencial de aprendizagem.
}

Percebe-se que a professora considera relevante os conhecimentos abordados no material pedagógico, pois possibilitam o aprimoramento das funções psicológicas superiores dos estudantes inseridos em escolas do campo. Há de se ponderar que Pianoviski (2017) apontou o descaso com a população marginalizada na sociedade, situando que não há estímulos eficazes para o desenvolvimento das funções psicológicas superiores dos estudantes oriundos do meio rural.

Ao propor um material pedagógico que abarque as escolas do campo busca contribuir com a superação da desconsideração com os sujeitos que as compõem. Com base numa teoria histórica e crítica que considere a totalidade humana, o PENeuroPsiE ao contar com o olhar de professores da área da educação do campo não vai de encontro ao imaginário coletivo e depreciativo do sujeito do campo como "caipira preguiçoso", "ignorante", "tabaréu", 
"matuto" atrelado a coisas ruins, degradantes e atraso das comunidades rurais. Também nesta oposição, Santana (2019, p.11) ressalta que:

[...] são necessários investimentos da psicologia na educação do campo, pois as relações e interação estabelecidas nas escolas influenciam os processos psicológicos superiores, que resultam das relações sociais, da aprendizagem e internalização da cultura, sendo que sua constituição procede do desenvolvimento histórico, das maneiras ativas que as pessoas se relacionam com uma dada realidade, ou seja, com o contexto em que vivem.

Uma das problemáticas da Educação do Campo apresentada por Souza (2008, p.1098) é sobre a formação dos professores, que estes profissionais "nem sempre têm formação escolar superior para atuar no magistério e poucos têm acesso a bibliotecas ou materiais didáticos para desenvolver um trabalho pedagógico que vá ao encontro da educação do campo". É nesta perspectiva, que os materiais pedagógicos do PENeuroPsiE visam contribuir com a formação inicial e continuada de professores, para que se concretize uma educação qualitativa para a população do campo. A P2 ainda relata que:

Com relação ao conteúdo para o $5^{\circ}$ ano do ensino fundamental deve estar fundamentado nos interesses dos alunos, nos seus conceitos espontâneos, estabelecendo a relação com a ciência, com o conhecimento científico elaborado ao longo da história da humanidade.

Portanto, para atuar em contextos de escolas do campo os professores necessitam considerar concepções no âmbito da Psicologia da Educação que possibilitem a ampliação dos saberes das diferentes comunidades e povos do campo desprovidos dos meios de produção. Considera-se que é imprescindível a internalização dos saberes historicamente produzidos, assim como a valorização da identidade do homem que vive e produz no campo, o que requer a formação de profissionais qualificados, com uma visão crítica e transformadora em relação a sociedade de classes, para que ocorra mediações pedagógicas voltadas à emancipação dos camponeses. No olhar da P2:

Os alunos precisam ir além do senso comum e se apropriar dos conhecimentos científicos acumulados ao longo de sua história. Muitas vezes a escola subestima a capacidade dos alunos e não possibilitam este avanço no desenvolvimento das capacidades intelectuais.

Neste sentido, a educação deve proporcionar condições para que a população camponesa se aproprie dos conhecimentos historicamente produzidos e para um posicionamento crítico diante da sociedade capitalista que está inserida. Para isso, deve levar em consideração as várias dimensões, para discutir as questões de exploração, melhores condições de vida e de trabalho, para que essa população tenha uma visão da totalidade e dos determinantes sociais que influenciam as suas vidas no campo, sem desconsiderar os seus saberes neste processo. 
As participantes deste estudo P2, P4 e P5 consideram as atividades propostas no PENeuroPsiE como motivadora à participação dos estudantes devido ao interesse deles nas áreas do conhecimento que o material abrange. Além disso, a linguagem utilizada é de fácil compreensão, com novidade, inovação dos recursos e formas interativas de construção do conhecimento "saindo da posição passiva que historicamente são colocados e tornando-os protagonistas de suas aprendizagens" (P2).

Contudo, o P1 sinalizou a necessidade de adaptar os recursos do PENeuroPsiE para a realidade vivenciada em assentamentos de reforma agrária e por utilizarem a pedagogia da alternância. Outra ponderação realizada por P2, que "não acredito muito em livros prontos feitos para massa de educandos, acredito em projetos baseados na realidade dos educandos e comunidade escolar", suscita reflexões acerca desta versão preliminar deste programa e suas intenções.

Entender sobre o funcionamento do cérebro, sua plasticidade e a importância da mediação pedagógica para o desenvolvimento das funções psicológicas superiores podem influenciar a conscientização de professores e crianças de que a memória, atenção, emoção, inteligência, linguagem e pensamento são desenvolvidos na interação com o contexto social, histórico e cultural. Por isso, é necessário empreender esforços na construção de recursos pedagógicos adequados ao processo de ensino-aprendizagem prazeroso e motivador na temática em discussão (SANTANA, 2019a, p.2).

A análise de Pianoviski (2017) realizada sobre o processo de ensino e aprendizagem em escolas rurais multisseriadas considerou os determinantes internos e externos, a partir da psicologia histórico-cultural e da pedagogia histórico-crítica. Em relação a formação inicial e continuada de educadores do campo, destacou que devido ao fato dos professores não receberem uma orientação pedagógica voltada às particularidades dos contextos rurais, reproduziam práticas alienantes e descontextualizadas.

Essa ideia é afirmada também na pesquisa de Bezerra e Silva (2018) com 05 professoras em um assentamento de reforma agrária, com o intuito de identificar os elementos mediadores que limitam o processo de apropriação da política de educação do campo. Como resultados, identificaram que a maioria das professoras ao ingressar nas escolas do campo não receberam mediação potencializadora em relação às políticas de educação do campo, mas por meio de apostilas descontextualizadas ao que se opõe ao que prevê as políticas. Ainda revelaram que ocorre uma omissão em relação a formação de professores do campo por parte dos gestores municipais e, que havia uma política de terceirização do projeto político pedagógico e currículo escolar, nas práticas pedagógicas encontra-se o pragmatismo na concepção de educação do campo (BEZERRA; SILVA, 2018). 
Em vista desses achados de Pianoviski (2017) e Bezerra e Silva (2018), a avaliação do PENeuroPsiE por parte de profissionais que trabalham na educação do campo, consequentemente, possibilitará sua melhora visando disponibilizar um recurso pedagógico com validade ecológica. A análise dos dados desta pesquisa aponta como relevante ajustes neste programa, porém ele possibilita benefícios para os professores e estudantes, contribuindo com a interação no contexto de sala de aula, a compreensão sobre a aprendizagem e o cérebro, podendo influenciar de forma positiva o ensino e aprendizagem dos estudantes que estudam em escolas do campo.

Cabe reiterar as ideias de Vygotsky sobre o professor como o mediador experiente que deve auxiliar o estudante na construção de conhecimentos científicos, acerca do mundo e dos objetos culturais utilizados na sociedade (SOUZA; DUQUE; COELHO, 2018). Desse modo, compreender o funcionamento do cérebro-biológico-sócio-histórico-cultural e o desenvolvimento das funções psicológicas superiores, possibilita considerar o homem em sua totalidade, numa realidade objetiva, em que a teoria é parte imprescindível da formação do concreto e que pode desvelar as contradições e buscar a superação das disparidades sociais.

\section{Considerações finais}

Esta pesquisa colocou em diálogo a Psicologia da Educação e Educação do Campo, por meio da identificação das concepções de professores que atuaram na área da Educação do Campo sobre as contribuições da Psicologia da Educação e dos recursos pedagógicos do Programa Escola Neuropsieducação (PENeuroPsiE), assim como ampliar a discussão sobre a Psicologia Rural. Para isso, foi realizada uma pesquisa qualitativa e exploratória que contou com a participação de 5 participantes da área de Educação do Campo.

Os participantes deste estudo sinalizaram a importância da Psicologia da Educação na formação de professores de maneira interdisciplinar, reflexiva e articulada ao contexto, e a psicologia escolar como um recurso importante para o cotidiano escolar. Apontaram os conhecimentos oriundos da Psicologia da Educação como importantes para entender os processos de aprendizagem e desenvolvimento, a particularidade dos sujeitos do campo e traçar meios para o seu aprendizado.

A Psicologia da Educação numa perspectiva crítica na formação de professores do campo irá possibilitar a compreensão de aspectos que interferem no processo de desenvolvimento e aprendizagem dos indivíduos, ou seja, ao considerar e tomar o homem em sua totalidade. Os participantes afirmaram utilizar em algum momento o conhecimento da Psicologia da Educação para embasar suas práticas pedagógicas. Portanto, evidencia-se a 
importância da inserção da Psicologia da Educação na formação de professores do campo articulada ao contexto, possibilitando a compreensão das demandas educativas existentes.

Cabe situar a importância de o PENeuroPsiE ser avaliado pelos sujeitos da Educação do Campo visando verificar a sua adequabilidade ou não para estudantes desta modalidade de educação, assim a percepção dos professores sobre esse recurso pedagógico irá auxiliar nos seus ajustes futuros. Os participantes deste estudo consideraram o PENeuroPsiE relevante, inovador e motivador para o desenvolvimento das funções psicológicas superiores e apropriação dos conhecimentos abordados. Contudo, há necessidade de adaptá-lo à realidade vivenciada pelos estudantes em assentamentos de reforma agrária e em escolas que adotam a Pedagogia da Alternância.

Os achados desta pesquisa contribuem com o aprimoramento do PENeuroPsiE e no avanço do debate na área da Psicologia Rural e Psicologia da Educação, consequentemente, na formação de professores que atuam em contextos rurais. Contudo, pesquisas futuras são necessárias e poderão ser desenvolvidas com os próprios estudantes do Ensino Fundamental I, da Educação do Campo que, consequentemente, contribuirão com o aprimorando do PENeuroPsiE e a apropriação do conhecimento científico por parte dos participantes.

\section{Referências}

ALMEIDA, Patrícia Cristina Albieri de; AZZI, Roberta Gurgel. A Psicologia da Educação como um saber necessário para a formação de professores. Temas em psicologia, vol. 15, n. 1, 41 - 55, 2007. Disponível em: http://pepsic.bvsalud.org/pdf/tp/v15n1/06.pdf. Acesso em: 25 mar. 2020.

ALVES, Zélia Maria Mendes Biasoli. Contribuições da psicologia ao cotidiano da escola: Necessárias e adequadas. Paidéia FFCLRP-USP, Rib.Preto, fev/ago 1997. Disponível em: https://doi.org/10.1590/S0103-863X1997000100007. Acesso em: 19 mar. 2020.

ANTUNES, Mitsuko Aparecida Makino. Psicologia Escolar e Educacional: história, compromissos e perspectivas. Psicol. Esc. Educ. (Impr.), Campinas, v. 12, n. 2, p. 469-475, dezembro de 2008.2 Disponível em $<$ http://www.scielo.br/scielo.php?script=sci_arttext\&pid=S141385572008000200020\&lng=en\&nrm=iso>. Acesso em 30 de abril de 2020.

ARROYO, Miguel González. A escola do campo e a pesquisa do campo: metas. In: MOLINA, M. (Org.). Educação do Campo e pesquisa: questões para reflexão. Brasília: Ministério do Desenvolvimento agrário, 2006.

BEZERRA, Delma Rosa dos Santos; SILVA, Ana Paula Soares da. Educação do Campo: apropriação pelas professoras de uma escola de assentamento. Psicologia Escolar e 
Educacional, SP. Volume 22, Número 3, setembro/dezembro de 2018. Disponível em: http://dx.doi.org/10.1590/2175-35392018032108. Acesso em: 21 mai. 2020.

CHAMON, Edna Maria Querido de Oliveira. As dimensões da Educação do Campo. Revista do Centro de Educação, vol. 41, núm. 1, enero-abril, 2016, pp. 183- 195. Disponível em: https://periodicos.ufsm.br/reveducacao/article/view/17979. Acesso em: 08 mai. 2020.

GIL, Antônio Carlos. Como elaborar projetos de pesquisa. 4. ed. - São Paulo: Atlas, 2002.

GIL, Antônio Carlos. Métodos e técnicas de pesquisa social. 6. ed. - São Paulo: Atlas, 2008. LAKATOS, Eva Maria; MARCONI, Marina de Andrade. Fundamentos de metodologia científica. 5. ed. São Paulo: Atlas, 2003.

LANDINI, Fernando. La noción de psicología rural y sus desafios en el contexto Latinoamericano. In: LANDINI, Fernando (Org.). Hacia una psicología rural latinoamericana. Ciudad Autónoma de Buenos Aires: CLACSO. 2015, pp.21-34. E-Book. Disponível em: <http://www.comunidadeslatinoamericanas.uchile.cl/noticias/hacia_una_psicologia_rural_libr o_terminado.pdf >. Acesso em: abr. 2020.

MARTINS, Lígia Márcia. As contribuições da psicologia histórico cultural para a Educação do Campo. Revista Binacional Brasil Argentina: Diálogo entre às Ciências, 3(2), pp. 86 a 107, dezembro, 2014. Disponível em: <http://periodicos.uesb.br/index.php/rbba/article/viewArticle/4594 >. Acesso em: dez. 2017. MAZZEU, Lidiane Teixeira Brasil. A pedagogia histórico-crítica como expressão teórica do marxismo na educação e a crítica à formação por competências. Revista de Educação PUCCampinas, Campinas, n. 23, p. 45-53, novembro 2007. Disponível em: http://periodicos.puccampinas.edu.br/seer/index.php/reveducacao/article/view/168. Acesso em: 08 mai. 2020.

MONTEIRO, Rosa Cristina. Educación y ruralidades contemporáneas. Aportes psicológicos para el debate. In: Landini, Fernando (Org.) Hacia una psicología rural latino-americana. 1a ed. - Ciudad Autónoma de Buenos Aires: CLACSO, 2015, pp.103-106. E-Book. Disponível em: http://www.comunidadeslatinoamericanas.uchile.cl/noticias/hacia_una_psicologia_rural_libro _terminado.pdf. Acesso em: 13 mai. 2020.

MORETTI, Vanessa Dias; ASBAHR, Flávia da Silva Ferreira; RIGON, Algacir José. O humano no homem: os pressupostos teórico-metodológicos da teoria histórico-cultural. Psicol. Soc., Florianópolis, v. 23, n. 3, p. 477-485, dez. 2011. Disponível em: $<$ http://www.scielo.br/scielo.php?script=sci_arttext\&pid=S010271822011000300005\&lng=en\&nrm=iso>. Acesso em: 30 abr. 2020. 
MURTAGH, Sofía. La educación en el ámbito rural. Desafíos para la psicología. In: Landini, Fernando (Org.). Hacia una psicología rural latino-americana. Ciudad Autónoma de Buenos Aires: CLACSO, 2015. pp.283-292. E-Book. Disponível em: http://www.comunidadeslatinoamericanas.uchile.cl/noticias/hacia_una_psicologia_rural_libro _terminado.pdf. Acesso em: 13 mai. 2020.

NETO-BEZERRA, Luiz. Educação do Campo ou educação no campo? Revista HISTEDBR On-line, Campinas, n.38, p. 150-168, jun.2010. Disponível em: https://doi.org/10.20396/rho.v10i38.8639696. Acesso em: 12 mai. 2020.

PASQULINI, Juliana Campregher; MAZZEU, Lidiane Teixeira Brasil. Em defesa da escola: uma análise histórico-crítica da educação escolar. Educação em Revista, Marília, v. 9, n. 1, p. 2008. 77-92, Disponível em: http://www2.marilia.unesp.br/revistas/index.php/educacaoemrevista/article/view/627/510. Acesso em: 15 mai. 2020.

PIANOVSKI, Regina Bonat. Ensino e aprendizagem em escolas rurais multisseriadas e as contribuições da psicologia histórico-cultural e da pedagogia histórico-crítica. 225f.Tese (Doutorado) - Universidade Tuiuti do Paraná: Curitiba, 2017. Disponível em: $<$ https://sucupira.capes.gov.br/sucupira/public/consultas/coleta/trabalhoConclusao/viewTrabal hoConclusao.jsf?popup=true\&id_trabalho=5020152>. Acesso em: jan. 2018.

SANT`ANNA, Patrick Ronan; GEBER, Saulo Pfeffer; TETU, Viviane. Contribuições da psicologia da educação: Percepção de professores do ensino fundamental I. Psic. da Ed., São Paulo, 49, $2^{\text {o }}$ sem. de 2019, pp. 79-87. Disponível em: http://pepsic.bvsalud.org/scielo.php?script=sci_abstract\&pid=S1414-69752019000200009. Acesso em: 14 abr. 2020.

SANTANA, Maria Luzia da Silva. Contributos e desafios da psicologia para a Educação do Campo. Revista ESPACIOS, vol. $40 \quad\left(\mathrm{~N}^{\mathrm{o}}\right.$ 23), 2019. s/p. Disponível em: https://www.revistaespacios.com/a19v40n23/19402329.html > Acesso em: 13 de março de 2020.

SANTANA, Maria Luzia da Silva. Programa Escola Neuropsieducação (PENeuroPsiE): um recurso pedagógico para aprendizagem de neurociências e processos psicológicos superiores a partir da psicologia sócio-histórica cultural. Vozes dos Vales, v. 15, p. 1-12, 2019a. Disponível em: http://site.ufvjm.edu.br/revistamultidisciplinar/files/2019/05/Maria0102.pdf Acesso em: 13 de março de 2020.

SILVA, Cleânia de Sales; NASCIMENTO, Adriana Loiola do. Papel da Psicologia da Educação na formação docente: o que pensam os alunos do plano nacional de formação de professores da educação básica / universidade federal do Piauí. Revista do Plano Nacional 
de Formação de Professores da Educação Básica / Universidade Federal do Piauí,

Teresina, v. 1, n. 1, p. 107-129, jul. / dez. 2013. Disponível em: https://ojs.ufpi.br/index.php/parfor/article/view/1512. Acesso em: 15 mai. 2020.

SOUZA, Daniel Cerqueira de; DUQUE, Andrews do Nascimento; COELHO, Ingrid Mesquita. Contribuições da psicologia aos contextos educacionais. RECH- Revista Ensino de Ciências e Humanidades - Cidadania, Diversidade e Bem Estar on line, vol. i, número 1, jan-jun, 2018, p. 192-221. Disponível em:

https://periodicos.ufam.edu.br/index.php/rech/article/view/4763. Acesso em: 14 abr. 2020.

SOUZA, Maria Antônia de. Educação do Campo: políticas, práticas pedagógicas e produção científica. Educ. Soc., Campinas, vol. 29, n. 105, p. 1089-1111, set. /dez. 2008. Disponível em: https://www.scielo.br/pdf/es/v29n105/v29n105a08.pdf. Acesso em: 12 mai. 2020.

ZUCOLOTO, Marcele Pereira da Rosa. Contribuições da psicologia a educação básica e o problema da psicologização da educação: uma revisão narrativa. Rev. HISTEDBR On line, Campinas, v.18, n.4 [78], p.1195-1208, out. /dez. 2018. Disponível em: https://periodicos.sbu.unicamp.br/ojs/index.php/histedbr/article/view/8652472. Acesso em: 10 mar. 2020. 